\title{
The Relations between Disability and Environmental Factors: A Pilot Study in Iranian Older Adults
}

\author{
Mohammadreza Shahbazi $^{1}$, Mahshid Foroughan ${ }^{2}$, Mahdi Rahgozar ${ }^{3}$ \& Reza Salmanroghani ${ }^{4}$ \\ ${ }^{1}$ Aging Department, University of Social Welfare and Rehabilitation Sciences, Tehran, Iran \\ ${ }^{2}$ Iranian Research Center on Aging, University of Social Welfare and Rehabilitation Sciences, Tehran, Iran \\ ${ }^{3}$ Department of Biostatistics, University of Social Welfare and Rehabilitation Sciences, Tehran, Iran \\ ${ }^{4}$ Department of Clinical Science, University of Social Welfare and Rehabilitation Sciences, Tehran, Iran \\ Correspondance: Mahshid Foroughan, Iranian Research Center on Aging, University of Social Welfare \& \\ Rehabilitation Sciences, Tehran, Iran. Tel: 98-2-1228-0004. E-mail: m_foroughan@yahoo.com
}

\author{
Received: January 20, 2016 Accepted: March 24, 2016 Online Published: April 29, 2016 \\ doi:10.5539/gjhs.v8n12p87 URL: http://dx.doi.org/10.5539/gjhs.v8n12p87
}

\begin{abstract}
Objective: This study explored disability and its correlations with the environmental factors in a group of Iranian older adults.

Materials and Methods: A cross sectional study was performed. One hundred participants receiving adult day care services in Kahrizak center in Iran were selected by using the complete enumeration method. The World Health Organization Disability Assessment Schedule 2 (WHODAS II) and the Craig Hospital Inventory of Environmental Factors (CHIEF) questionnaires were used to collect data.

Results: The mean score of disability was $20.61 \pm 13.66$, and the scores were higher in women compared to men $(\mathrm{P}=0.001)$. Among the CHIEF-25 items, the most frequently perceived barrier by the participants was transportation followed by home design and unavailability of health care services. There was a significant association between the disability scores and the environmental factors $(\mathrm{P}<0.001)$. Also, significant relationships were found between the disability and all the subscales investigated in the study (polices, physical/structural, attitude/support, services/assistance) $(\mathrm{P}<0.001)$.
\end{abstract}

Conclusion: Appropriate transportation, availability to health care services and removing physical/structural barriers should be taken in consideration.

Keywords: aging, day care, disability, environmental factors, older persons

\section{Introduction}

In the last few decades the attitude towards disability has altered, and recently disability is viewed as the outcome of interaction between health conditions (diseases, disorders and injuries) and contextual factors (environmental and personal factors). This has led to a new definition of disability, introduced by the International Classification of Functioning, Disability and Health (ICF): "disability is a multidimensional issue that covers impairment, activity limitation and participation restrictions" (WHO, 2001). Environmental factors make up the physical, social and attitudinal environment, which play roles as facilitators or barriers that include products and technology, natural environment and human-made changes to environment, support and relationships, attitudes, services, systems and policies (WHO, 2001).

A medical approach to disability often leads to treatment strategies that focus on individuals and their deficits rather than their function, and environmental barriers. Assuming that changing deficits to promote function may not be possible in many cases, it seems that turning to environmental, personal, and social factors may be more rewarding. As many authors of the field have expressed, in order to improve rehabilitation services, we need to consider the social and environmental factors affecting disability (Dijkers, Yavuzer, Ergin, Weitzenkamp, \& Whiteneck, 2002; Ephraim, MacKenzie, Wegener, Dillingham, \& Pezzin, 2006; Han et al., 2005).

Most research investigating disability has focused on self care and living skills, using the Katz activities of daily living (ADL), or the Barthel index for assessing activities of daily living, and the Lawton instrumental activities of daily living (IADL) scale to assess independence living skills (Ania et al., 1997; Beland \& Zunzunegui, 1999; 
Hoeymans, Feskens, van den Bos, \& Kromhout, 1997; Lin, 2000; Penninx et al., 2000; Rosa, Benicio, Latorre, \& Ramos, 2003; Serraino, Fratino, \& Zagonel, 2001; Taş et al., 2007). Also the studies considering the area of environmental factors as important ones are limited, most of them focused on physical barriers (Dijkers et al., 2002; Harrison-Felix, 2001). Few studies have considered other important environmental factors and found different results. For example; Dijkers et al. (2002) compared environmental impact on social participation in community-dwelling individuals with spinal cord injury in the USA and Turkey. The results showed that the two groups experienced different barriers, although they have the same level of dependency. Turkish participants more often reported unavailability of health care services and attitude barriers; However, USA participants more often noted unavailability of help in home (Dijkers et al., 2002). Other studies have demonstrated that natural and transportation barriers have the most effect on disability (Ephraim et al., 2006; Han et al., 2005; Leff, Stallones, Xiang, \& Whiteneck, 2010; Keysor et al., 2010; Nobakht, Rassafiani, \& Rezasoltani, 2011; Whiteneck et al., 2004). A few studies have shown different barriers such as the unavailability of services, and policy barriers (Nobakht et al., 2011), unavailability of technology, especially, aid instruments (Layton, 2012), and attitude and support barriers (Nichols, Tchounwou, Mena, \& Sarpong, 2009).

During the last decades, the aging population has been increasing, which has been called a "universal phenomenon" (Schoeni and Ofstedal, 2010). The aged population of Iran has also been increasing rapidly; the rate of Iranian population 60+ (60 years old has been determined as the onset of old age in Iran, according to the WHO recommendation) has increased from 7.3 to 8.2 within 10 years since 2006. On the other hand, health conditions and disabilities increase with age (Hoeymans et al., 1997; Sean Morrison \& Meier, 2003). This has created major challenges for the health systems and has created a great overload on the rehabilitation services.

As mentioned before, environmental factors act as facilitators or barriers. Moreover, individuals have experienced different barriers in different societies. So, we decided to design this pilot study aimed to assess the disability and related environmental factors in older adults receiving adult day care services. To the best of our knowledge, this is the first effort in this field in our country.

\section{Materials and Methods}

\subsection{General Description}

This is a cross-sectional, correlation study. All the participants $(n=100)$ at least 60 years old who were receiving adult day care services during June to August 2014 in Kahrizak Center, the only adult day center in Alborz Province in Northwest of Iran, participated in the study. The center provides the comprehensive rehabilitation services including physiotherapy, occupational therapy, speech therapy (as needed by the consumer and prescribed by the professionals), educational activities (social life skills, healthy lifestyle, and self-care training programs), nutrition counseling, cognitive enhancement that including; memory reinforcement techniques and psycho-social interventions such as art therapy, individual and group therapy, and recreational activities. The enumeration method was used for the sampling. Inclusion criteria were $\geq 60$ years of age, the ability to communicate and respond to the questionnaires, and consenting to participate in the study. The participants were informed that they were free to leave the study at any time they want. The attrition rate was zero, and no one left the study until the data collection was completed. The study was approved by the Ethics Committee of the University of Social Welfare and Rehabilitation Sciences (the Ethics Committee Approval Number: USWR.REC.1392.109).

\subsection{Assessment Tools}

The World Health Organization Disability Assessment Schedule II(WHODAS II) 36-item questionnaire (Ustun et al., 2010) was used to assess the disability of older individuals. This tool has developed by the World Health Organization and assesses disability in the six domains of understanding and communication, getting around, self-care, getting along with people, life activities and participation. There are two ways to compute the scores of the WHODAS II, namely simple and complex scoring. The complex way, known as item response theory-based scoring, was used in this study. It takes into account multiple levels of difficulty for each WHODAS II item. It takes the coding for each item response as "none=0", "mild=1", "moderate=2", "severe=3" and "extreme=4" separately, and then uses an algorithm to determine the total score by differentially weighting the items and the levels of severity. The scoring has three steps: summing of recoded item scores within each domain, summing of all six domain scores, converting the summary score into a metric ranging from 0 to 100 (where $0=$ no disability; $100=$ full disability). In addition to the total score, WHODAS II also makes it possible to compute domain-specific scores. The appropriate psychometric properties of the WHODAS II have been shown [Cronbach's alpha $=0.86$, Intraclass Correlation Coefficient $($ ICC $)=0.98$ ] (Ustun et al., 2010). It also has been translated into Persian and validated in Iranian older adults (Ardjomand-Hessabi, Mahmudi, Kamali, \& Zeraati, 
2007).

The Criag Hospital Inventory of Environmental Factors (CHIEF) 25-items questionnaire (Harrison-Felix, 2001) was used to assess the environmental factors. The questionnaire was developed by a professional group in the Criag hospital according to the International Classification of Functioning, Disability and Health (ICIDH-2) published in 1999 (WHO, 1999). The focus of the CHIEF is on the quantification of barriers experienced within five domains of environmental factors: Policies; Physical and Structural; Work and School; Attitudes and Support; Services and Assistance. Respondents rate the frequency with which they encounter barriers (daily, weekly, monthly, less than monthly, or never) on the 25 items of the CHIEF reflecting elements of the environment. When respondents indicate that they encounter environmental barriers at any frequency other than never, a follow-up question is asked about whether they consider the barrier to be a big or a little problem. Scoring of each CHIEF item is the product of the frequency score ("never=0", "less than monthly=1", "monthly=2", "weekly=3" and "daily=4"), the magnitude of impact score ("little problem=1" and "big problem $=2$ ") to produce an item score, frequency magnitude product score, ranges from $0-8$. Total scores across the 25 items were calculated at the average frequency score, the average magnitude score and the frequency magnitude product score across all of the items. Therefore, higher scores indicate greater environmental barriers. The CHIEF25-items has shown appropriate psychometric properties (ICC=0.93) ((Harrison-Felix, 2001). The questionnaire has been translated into Persian and validated in Iran (Nobakht et al., 2011). In this study, work and school domains were not assessed because of the participants' age and job conditions. The participants did not work at the time of study. The questionnaires were completed in face to face interview by trained assessors.

\subsection{Statistical Analysis}

Descriptive statistics, chi-square, Mann-Whitney U, Kruskal- Wallis, and Independent test were used for distributions of various characteristics of the study sample including demographic, income, comparing mean scores of disability in WHODAS II and environmental factors (CHIEF25-items). In addition, multiple linear regression, and Spearman correlation coefficient were used for finding correlation between disability and environmental factors (CHIEF25-items). Kolmogorov-Spirnov test was used for assessing normality of distributions. All descriptive and inferential statistical analyses were realized using SPSS version 16.0. (SPSS Inc, 2007).

Table 1. Individual and household characteristics of the study sample

\begin{tabular}{llllll}
\hline \multirow{2}{*}{ Marital Status } & Category & $\begin{array}{l}\text { Total }(\mathrm{n}=100) \\
\mathrm{n}(\%)\end{array}$ & $\begin{array}{l}\text { Men }(\mathrm{n}=36) \\
\mathrm{n}(\%)\end{array}$ & $\begin{array}{l}\text { Women }(\mathrm{n}=64) \\
\mathrm{n}(\%)\end{array}$ & \multirow{2}{*}{$\begin{array}{l}\text { (\%) } \\
\text { Education }\end{array}$} \\
& Married & $66(66.0)$ & $34(94.4)$ & $32(50.0)$ & $<0.001^{\mathrm{a}}$ \\
& Single & $34(34.0)$ & $2(5.6)$ & $32(50.0)$ & \\
Age & Illiterate & $56(56.0)$ & $20(55.6)$ & $36(53.2)$ & \multirow{2}{*}{$0.63^{\mathrm{a}}$} \\
Income $^{\mathrm{d}}$ & Low & $15(15.0)$ & $4(11.1)$ & $11(17.2)$ & \\
& Literate & $29(29.0)$ & $12(33.3)$ & $17(26.6)$ & $0.01^{\mathrm{b}}$ \\
\hline
\end{tabular}

${ }^{\mathrm{a}}$ Chi Square, ${ }^{\mathrm{b}} \mathrm{T}$ - test, ${ }^{\mathrm{c}}$ Mann- Whitney-U, ${ }^{\mathrm{d}}$ Iranian Currency- Rials

\section{Results}

\subsection{Participant's Characteristics}

The sample included one hundred older individuals with the mean age of the $72.39 \pm 6.75$ years, and the age range from 61 to 88 years. Most of the paticipants were women and illiterate. Significant differences were found between men and women in age $(\mathrm{P}=0.013)$, marital status $(\mathrm{P}<0.001)$ and income $(\mathrm{P}=0.025)$ (Table 1).

The mean score of environmental factors was $0.62 \pm 0.85$. No significant differences were observed between men and women. In the subscales, most often, barriers were found in physical/structural, attitude/support and services/assistance subscales. Significant differences were found between men and women in attitude/support $(\mathrm{P}=0.003)$ and services/assistance $(\mathrm{P}=0.033)$. Both subscale scores were higher in women (Table 2$)$. 


\subsection{The CHIEF 25-Items}

Among the CHIEF 25-items, the greatest barrier was transportation, followed by home design and unavailability of health care services Women more often reported transportation, unavailability of health care services and men more often noted surroundings, transportation and natural environment barriers. The Mann-Whitney $U$ test revealed that there were significant differences between men and women in social support $(P=0.021)$, attitude in community $(P=0.028)$, support in home $(P=0.025)$, attitude at home $(P=0.023)$, discrimination $(P=0.026)$, unavailability of health care services $(P=0.044)$, help in home $(P=0.038)$ and help in community $(P=0.038)$. In all above- mentioned items, women had higher scores. Nobody answered the question about technology. Table 2 shows mean scores of domains of disability and subscales of environmental factors (CHIEF 25 -items).

Table 2. Comparing mean scores of WHODAS II disability scores and environmental factors (CHIEF25-items) between men and women

\begin{tabular}{|c|c|c|c|c|c|c|c|c|}
\hline \multirow{2}{*}{ Variables } & & \multicolumn{2}{|l|}{ Total } & \multicolumn{2}{|l|}{ Men } & \multicolumn{2}{|c|}{ Women } & \multirow{2}{*}{$-\mathrm{P}$} \\
\hline & & Mean & $\mathrm{SD}$ & Mean & $\mathrm{SD}$ & Mean & $\mathrm{SD}$ & \\
\hline \multirow{26}{*}{ CHIEF- 25- items Environmental Factors } & Policies Subscales & 0.34 & 0.70 & 0.32 & 0.78 & 0.36 & 0.66 & $0.41^{\mathrm{a}}$ \\
\hline & Policies of business & 0.38 & 1.07 & 0.50 & 1.63 & 0.32 & 0.62 & 0.36 \\
\hline & Education policies & 0.38 & 0.91 & 0.27 & 0.87 & 0.43 & 0.93 & 0.13 \\
\hline & Services in community & 0.33 & 0.79 & 0.17 & 0.53 & 0.42 & 0.89 & 0.11 \\
\hline & Government policies & 0.29 & 0.75 & 0.33 & 1.06 & 0.27 & 0.55 & 0.26 \\
\hline & Physical/Structural Subscale & 0.79 & 1.17 & 0.80 & 1.36 & 0.78 & 1.08 & $0.93^{\mathrm{a}}$ \\
\hline & Home design & 0.99 & 1.83 & 0.60 & 1.57 & 1.18 & 1.94 & 0.07 \\
\hline & Surrounding & 0.77 & 1.60 & 1.13 & 2.27 & 0.58 & 1.11 & 0.72 \\
\hline & Design of community & 0.77 & 1.49 & 0.73 & 1.84 & 0.78 & 1.30 & 0.26 \\
\hline & Natural Environment & 0.63 & 1.23 & 0.73 & 1.62 & 0.58 & 1.00 & 0.48 \\
\hline & Technology & - & - & - & - & - & - & - \\
\hline & Attitudes/Support Subscale & 0.69 & 1.25 & 0.23 & 0.65 & 0.92 & 1.41 & $0.003^{\mathrm{a}}$ \\
\hline & Support in community & 0.71 & 1.54 & 0.27 & 0.87 & 0.93 & 1.75 & 0.02 \\
\hline & Attitude in community & 0.64 & 1.25 & 0.33 & 1.03 & 0.80 & 1.33 & 0.03 \\
\hline & Support in home & 0.68 & 1.69 & 0.17 & 0.53 & 0.93 & 1.99 & 0.02 \\
\hline & Attitudes at home & 0.63 & 1.67 & 0.13 & 0.43 & 0.88 & 1.98 & 0.02 \\
\hline & Discrimination & 0.78 & 1.72 & 0.23 & 0.63 & 1.05 & 2.01 & 0.03 \\
\hline & Services /Assistance Subscale & 0.68 & 0.94 & 0.41 & 0.83 & 0.81 & 0.97 & $0.03^{\mathrm{a}}$ \\
\hline & Transportation & 1.08 & 1.75 & 0.73 & 1.48 & 1.25 & 1.86 & 0.20 \\
\hline & Medical Care & 0.96 & 1.51 & 0.60 & 1.30 & 1.18 & 1.93 & 0.04 \\
\hline & Help in home & 0.73 & 1.48 & 0.37 & 1.07 & 0.92 & 1.63 & 0.04 \\
\hline & Education & 0.28 & 0.75 & 0.23 & 0.82 & 0.30 & 0.72 & 0.27 \\
\hline & Help in community & 0.63 & 1.31 & 0.27 & 0.87 & 0.82 & 1.46 & 0.04 \\
\hline & Information & 0.39 & 1.00 & 0.23 & 0.82 & 0.47 & 1.08 & 0.19 \\
\hline & Equipment & 0.87 & 1.64 & 0.53 & 1.36 & 1.08 & 1.75 & 0.11 \\
\hline & Total & 0.62 & 0.86 & 0.42 & 0.74 & 0.73 & 0.90 & $0.09^{\mathrm{a}}$ \\
\hline \multirow{7}{*}{ WHODAS II Disability Scores } & Understanding \& Communication & 16.66 & 15.40 & 12.77 & 11.93 & 18.61 & 16.63 & $0.05^{\mathrm{a}}$ \\
\hline & Getting around & 38.06 & 28.49 & 23.67 & 26.29 & 45.25 & 26.96 & $0.001^{\mathrm{b}}$ \\
\hline & Self-care & 8.49 & 13.50 & 6.68 & 11.14 & 9.39 & 14.54 & $0.41^{\mathrm{a}}$ \\
\hline & Getting alone with & 5.39 & 8.15 & 4.83 & 6.76 & 5.67 & 8.80 & $0.97^{\mathrm{a}}$ \\
\hline & Life activities & 27.51 & 25.08 & 17.72 & 24.79 & 32.41 & 23.96 & $0.001^{\mathrm{a}}$ \\
\hline & Participation & 27.49 & 18.89 & 19.71 & 17.79 & 31.38 & 18.34 & $0.005^{b}$ \\
\hline & Total & 20.61 & 13.66 & 14.20 & 11.42 & 23.82 & 13.63 & $0.001^{\mathrm{b}}$ \\
\hline
\end{tabular}

${ }^{\mathrm{a}}$ Mann Whitey-U, ${ }^{\mathrm{b}}$ T-test 
Table 3. Comparing WHODAS II disability scores with sex, education, and marital status categories

\begin{tabular}{lllll}
\hline & & \multicolumn{2}{l}{ Disability } & \multirow{2}{*}{$P$} \\
\cline { 3 - 4 } Sex & Man & Mean & SD & \\
& Women & 14.2 & 11.42 & \multirow{2}{*}{$0.001^{\mathrm{a}}$} \\
\multirow{2}{*}{ Education } & Illiterate & 23.82 & 13.63 & \\
& Reading and Writing & 24.47 & 17.71 & \multirow{2}{*}{$0.009^{\mathrm{b}}$} \\
\multirow{3}{*}{ Marital Status } & Elementary and Higher & 17.33 & 7.9 & \\
& Single & 14.36 & 10.29 & \\
\hline
\end{tabular}

${ }^{\mathrm{a} T}$ T-test, ${ }^{\mathrm{b}}$ Kruskal- Wallis

\subsection{Relationship between WHODAS II Disability Scores and the CHIEF 25-Items}

The Spearman correlation coefficient showed significant association between disability and environmental factors $(\mathrm{r}=0.73 ; \mathrm{P}<0.001)$. By increasing the environmental barriers, disability increased. All the 4 subscales of environmental factors investigated in this study including polices, physical/structural, attitude/support, services/assistance were significantly associated with disability ( $\mathrm{P}<0.001)$ (Table 4$)$. In addition, Table 5 shows the environmental factors $(\mathrm{P}<0.001)$ and income $(\mathrm{P}=0.021)$ effect on disability among older persons $(\mathrm{P}=0.021)$.

Table 4. Correlation coefficients between WHODAS II disability scores and environmental factor and its subscales (CHIEF25-items)

\begin{tabular}{lll}
\hline Variables & Correlation Coefficient & $P$ \\
\hline Policies & $0.58^{*}$ & $<0.001$ \\
Physical/structural & $0.69^{*}$ & $<0.001$ \\
Attitude/support & $0.64^{*}$ & $<0.001$ \\
Services/assistance & $0.66^{*}$ & $<0.001$ \\
Total & $0.73^{*}$ & $<0.001$ \\
\hline
\end{tabular}

*Spearman Correlation Coefficient

Table 5. Parameter estimates of WHODAS II disability scores with total environmental factors (CHIEF 25-items), age and income

\begin{tabular}{|c|c|c|c|c|c|}
\hline & \multicolumn{2}{|c|}{$\begin{array}{l}\text { Unstandardized } \\
\text { Coefficients }\end{array}$} & \multirow{2}{*}{$\begin{array}{l}\text { Standardized } \\
\text { Coefficients } \\
\text { Beta } \\
\end{array}$} & \multirow[t]{2}{*}{$\mathrm{t}$} & \multirow{2}{*}{$P$} \\
\hline & $\mathrm{B}$ & Std. Error & & & \\
\hline Constant & 1.25 & 11.70 & - & 0.11 & 0.915 \\
\hline Total score CHIEF-25 items & 11.66 & 1.19 & 0.73 & 9.78 & $<0.001$ \\
\hline Age & 0.20 & 0.16 & 0.09 & 1.25 & 0.215 \\
\hline Income & 0.00 & 0.00 & -0.18 & -2.35 & 0.021 \\
\hline
\end{tabular}

$\mathrm{R}^{2}=0.536$, ANOVA $(\mathrm{F}=33.11, P<0.001)$

\section{Discussion}

The results of this study showed that the mean score of disability was $20.61 \pm 13.66$ (Mild to moderate disability). Some studies showed the same results (Ardjomand-Hessabi et al., 2008; Donmez, Gokkoca, \& Dedeoglu, 2005). Significant differences were found between disability, sex and education. Disability was higher in women and people with low educational level. The highest disability score of the six domains referred to getting around domain. Most previous studies showed the same results; Donmez et al. (2005) reported disability score of Turkish older people aged 60 and older 23.0土19.9. They noted that women presented greater disability than men and that the most severe domains of disability were getting around and life activity. Jitapunkul et al. 
(2003) found that rate of disability of older people in Tailand increased with age and women were more disabled than men. In contrast, Scott and Collings (2010) showed that men had higher disability and Breslin, Gnam, Franche, Mustard and Lin (2006) found no significant differences between men and women. These differences may be due to different study design and sampling. These two studies investigated disability among people with age lower than 60 years old with mental disorders and depression. Alexandre et al. (2012) reported that gender difference and disability also related to type of disability. Ardjomand-Hessabi et al. (2007) demonstrated that disability among Iranian older people related to age, sex and education and also the most severe domains of disability were getting around, Life activity and participation. Donmez at el. (2005) showed the most severe disability were life activity and getting around. However, Rivera, Fried, Weiss \& Simonsick (2008) offered conceptual model that delimits some domains which are necessary to mobility (getting around); central nervous system, peripheral nervous system, musculoskeletal system, perceptual system and energy production. With regard to age related changes, functional decreasing in all these systems especially the high prevalence of musculoskeletal problems endangers the mobility. So finding getting around as severe disability in the present study also seems reasonable.

The results of the study revealed that the disability scores were significantly related to the environmental factors measured by the CHIEF 25 -items. By increasing environmental barriers disability increased as well. Significant relationships were found between the disability and the four subscales investigated in the study, i.e. policies, physical/structural, attitude/support and services/assistance. These findings are in line with the results of previous studies (Dijkers et al., 2002; Han et al., 2005; Leff et al., 2010). Dijkers et al. (2002) demonstrated that there were significant relationships between ADL and perceived environmental barriers. Also Han et al. (2005) found the same results with stronger relationship between ADL and perceived environmental barriers. It should be noted that assessing ADL by the Bartel questionnaire, used by Han et al. (2005) and the functional independence measure (FIM) used by Dijkers et al. (2002) are similar to some domains of the WHODAS II.

In addition, our study demonstrated that among the CHIEF 25 -items the greatest perceived barriers reported by participants were transportation followed by home design and unavailability to health care services. The results of some previous studies were in accord with these results (Dijkers et al., 2002 (Turkish participants); Ephraim et al., 2006; Leff et al., 2010; Keysor et al., 2010; Whiteneck et al., 2004). This was anticipated, because in recent years enough consideration has not been given to the transportation system, especially, providing appropriately accommodated vehicles needed by persons with disabilities and older individuals in Iran.

After the transportation barrier, barriers most often mentioned by older persons were home design and unavailability of health care services. It was predictable because most participants did not have enough income and ability to provide suitable furniture and appliances for designing an accommodated home. Moreover, it was not possible for them to remove physical barriers from their home and provide aid instruments needed. In the case of the availability of health services, we can address inadequate distribution of health services in the region, unavailability of medical professionals, and unavailability of proper transportation, which presents older persons with difficulties. The worst is that health care insurance companies do not provide adequate support for persons with disabilities and older persons.

On the other hand, some other studies have shown different barriers; help in home for Americans (Dijkers et al., 2002), unavailability of services and policy barriers (Nobakht et al., 2011), unavailability of technology, especially, aid instruments (Layton, 2012). Different population, methodology and statistical approaches in research plus social, cultural and economical differences might produce this dissimilarity.

According to Iranian culture, children and other members of family provide enough consideration and support to their elderly. Therefore, the older persons in this study experienced lower difficulties and barriers in help in home and help in community than other populations. Also, lower education and more illiteracy among the participants caused lower attention to information and technology barriers. This is why nobody answered the technology question.

There were some limitations in our study. The sample size was small, and there was only one adult day center in Alborze province. The day care services might affect on level of disability. These limitations might affect methodology and results. Further research with large sampling and randomized design are suggested.

\section{Conclusion}

The results of the study indicated that disability significantly related to environmental factors. Besides there were significant relationships between disability and all subscales investigated in the study, policies, physical/structural, attitude/support and services/assistance. 
The greatest perceived barrier reported by older persons was transportation, followed by home design and lack of availability of health care services. Therefore, appropriate transportation, availability of health care services and removal physical/structural barriers should be taken into consideration. Considering the higher disability and greater barriers experienced by women, priority should be given to rehabilitation programs and services.

\section{Acknowledgements}

The authors thank the Kahrizak charity foundation as well as the participants who made this study possible. And declare that not used any grant.

\section{Competing Interests Statement}

The authors declare that there is no conflict of interests regarding the publication of this paper.

\section{References}

Alexandre, T. S., Corona, L. P., Nunes, D. P., Santos, J. L., Duarte, Y. A., \& Lebrao, M. L. (2012). Gender differences in incidence and determinants of disability in activities of daily living among elderly individuals: SABE study. Arch Geronto Geriatr, 55(2), 431-437. http://dx.doi.org/10.1016/j.archger.2012.04.001

Ania Lafuente, B. J., Suarez Almenara, J. L., Guerra, H. L., Santana, A. J., Acosta Morales, C. D., \& Saavedra Rodriguez, J. M. (1997). Healthy aging and functional disability among the elderly inhabitants of the Canary Islands (Spain). Rev Esp. Salud Publica, 71(2), 161-171.

Ardjomand-Hessabi, M., Mahmudi, M., Kamali, M., \& Zeraati, H. (2007). Translation, Standardization World Health Organization Disability Assessment Schedule II (WHODAS II) in Iranian Elderly Population (Unpublished M.P.H, Theses). Tehran University of Medical Sciences, School of Public Health.

Beland, F., \& Zunzunegui, M. V. (1999). Predictors of functional status in older people living at home. Age Ageing, 28(2), 153-159. http://dx.doi.org/10.1093/ageing/28.2.153

Breslin, F. C., Gnam, W., Franche, R. L., Mustard, C., \& Lin, E. (2006). Depression and activity limitations: Examining gender differences in the general population. Soc Psychiatry Psychiatr Epidemiol, 41(8), 648-655. http://dx.doi.org/10.1007/s00127-006-0079-6

Dijkers, M. P., Yavuzer, G., Ergin, S., Weitzenkamp, D., \& Whiteneck, G. G. (2002). A tale of two countries: Environmental impacts on social participation after spinal cord injury. Spinal Cord, 40(7), 351-362. http://dx.doi.org/10.1038/sj.sc.3101310

Donmez, L., Gokkoca, Z., \& Dedeoglu, N. (2005). Disability and its effects on quality of life among older people living in Antalya city center Turkey. Arch Geronto Geriatr, 40(2), 213-223. http://dx.doi.org/10. 1016/j.archger.2004.08.006

Ephraim, P. L., MacKenzie, E. J., Wegener, S. T., Dillingham, T. R., \& Pezzin, L. E. (2006). Environmental barriers experienced by amputees: The Craig Hospital Inventory of Environmental Factors-Short Form. Arch Phys Med Rehabil, 87(3), 328-333. http://dx.doi.org/10.1016/j.apmr.2005.11.010

Han, C. W., Yajima, Y., Lee, E. J., Nakajima, K., Meguro, M., \& Kohzuki, M. (2005). Validity and utility of the Craig Hospital Inventory of Environmental Factors for Korean community-dwelling elderly with or without stroke. Tohoku J Exp. Med, 206(1), 41-49. http://dx.doi.org/10.1620/tjem.206.41

Harrison-Felix, C. (2001). The Craig hospital inventory of environmental factors, Version 3.0. In Craig Hospital, Research Department. Retrieved from https://craighospital.org/uploads/CraigHospital.ChiefManual.pdf

Hoeymans, N., Feskens, E. J., van den Bos, G. A., \& Kromhout, D. (1997). Age, time, and cohort effects on functional status and self-rated health in elderly men. Am J Public Health, 87(10), 1620-1625. http://dx.doi. org/10.2105/AJPH.87.10.1620

Jitapunkul, S., Kunanusont, C., Phoolcharoen, W., Suriyawongpaisal, P., \& Ebrahim, S. (2003). Disability-free life expectancy of elderly people in a population undergoing demographic and epidemiologic transition. Age Aging, 32, 401-405. http://dx.doi.org/10.1093/ageing/32.4.401

Keysor, J. J., Jette, A. M., LaValley, M. P., Lewis, C. E., Torner, J. C., Nevitt, M. C., \& Felson, D. T. (2010). Community environmental factors are associated with disability in older adults with functional limitations: The MOST study. J Gerontol. A Biol Sci Med Sci, 65(4), 393-399. http://dx.doi.org/10.1093/gerona/glp182

Layton, N. (2012). Barriers and facilitators to community mobility for assistive technology users. Rehabil. Res Pract., 454195. http://dx.doi.org/10.1155/2012/454195

Leff, M., Stallones, L., Xiang, H., \& Whiteneck, G. (2010). Disability, environmental factors and non-fatal injury. 
Inj. Prev., 16(6), 411-415. http://dx.doi.org/10.1136/ip.2010.028522

Lin, G. (2000). Regional assessment of elderly disability in the U.S. Soc. Sci Med, 50(7-8), 1015-1024. http://dx.doi.org/10.1016/S0277-9536(99)00351-2

Nichols, L., Tchounwou, P. B., Mena, L., \& Sarpong, D. (2009). The effects of environmental factors on persons living with HIV/AIDS. Int J Environ Res Public Health, 6(7), 2041-2054. http://dx.doi.org/10.3390/ijerph6 072041

Nobakht, Z., Rassafiani, M., \& Rezasoltani, P. (2011). Validity and reliabilityof Persian version of Craig Hospital Inventory of Environmental Factors (CHIEF) in children with cerebral palsy. Iranian Rehabilitation Journal, 9(13), 3-10.

Penninx, B. W., Ferrucci, L., Leveille, S. G., Rantanen, T., Pahor, M., \& Guralnik, J. M. (2000). Lower extremity performance in nondisabled older persons as a predictor of subsequent hospitalization. $J$ Gerontol.A Biol Sci Med Sci, 55(11), M691-M697. http://dx.doi.org/10.1093/gerona/55.11.M691

PSS Inc. (2007). Statistical Package for the Social Sciences (SPSS), Software Statistics 16.0. For Windows Version 16.0) Chicago: SPSS Inc. Retrieved from http://www.spss.com

Rivera, J., Fried, L., Weiss, C., \& Simonsick, E. (2008).At the tipping point: predicting severe mobility difficulty in vulnerable older women. $J$ Am Geriatr Soc, 56(8), 1417-1423. http://dx.doi.org/10.1111/j.1532-5415. 2008.01819.x

Rosa, T. E., Benicio, M. H., Latorre, M. R., \& Ramos, L. R. (2003). Determinant factors of functional status among the elderly. Rev Saude Publica, 37(1), 40-48.

Schoeni, R. F., \& Ofstedal, M. B. (2010). Key themes in research on the demography of aging. Demography, 47(Suppl), S5-15. http://dx.doi.org/10.1353/dem.2010.0001

Scott, K. M., \& Collings, S. C. (2010). Gender and the association between mental disorders and disability. $J$ Affect. Disord, 125(1-3), 207-212. http://dx.doi.org/10.1016/j.jad.2010.06.022

Sean Morrison, R., \& Meier, D. E. (2003). Geriatric palliative care. Oxford University Press.

Serraino, D., Fratino, L., \& Zagonel, V. (2001). Prevalence of functional disability among elderly patients with cancer. Crit Rev Oncol.Hematol., 39(3), 269-273. http://dx.doi.org/10.1016/S1040-8428(00)00130-X

Taş U., Verhagen, A. P., Bierma-Zeinstra, S. M., Hofman, A., Odding, E., Pols, H. A., \& Koes, B. W. (2007). Incidence and risk factors of disability in the elderly: The Rotterdam Study. Prev.Med, 44(3), 272-278. http://dx.doi.org/10.1016/j.ypmed.2006.11.007

Ustun, T. B., Chatterji, S., Kostanjsek, N., Rehm, J., Kennedy, C., Epping-Jordan, J., ... \& Pull, C. (2010). Developing the World Health Organization Disability Assessment Schedule 2.0. Bull. World Health Organ, 88(11), 815-823. http://dx.doi.org/10.2471/BLT.09.067231

Whiteneck, G., Meade, M. A., Dijkers, M., Tate, D. G., Bushnik, T., \& Forchheimer, M. B. (2004). Environmental factors and their role in participation and life satisfaction after spinal cord injury. Arch Phys Med Rehabil., 85(11), 1793-1803. http://dx.doi.org/10.1016/j.apmr.2004.04.024

World Health Organization. (1999). International Classification of Functioning, Disability and Health (ICIDH-2). Geneva: World Health Organization.

World Health Organization. (2001a). International Classification of Functioning, Disability and Health (ICF). Geneva: World Health Organization.

World Health Organization. (2001b). International Classification of Functioning, Disability and Health (ICIDH-2). Geneva: World Health Organization.

World Health Organization. (2001c). International Classification of Functioning, Disability and Health (ICF). Geneva: World Health Organization.

\section{Copyrights}

Copyright for this article is retained by the author(s), with first publication rights granted to the journal.

This is an open-access article distributed under the terms and conditions of the Creative Commons Attribution license (http://creativecommons.org/licenses/by/3.0/). 